\section{Commentary: Mesothelioma ... moving the needle on locoregional control has invited aggressive treatment options for limited distant metastases}

Michael Lanuti, MD

Distant sites of failure after aggressive multimodality therapy for mesothelioma have been less common than locoregional recurrence. Case reports of oligometastatic mesothelioma to the brain have been reported dating back to $1995 .{ }^{1,2}$ These reports have highlighted local aggressive therapy with limited long-term survival. In this issue of JTCVS Techniques, $\mathrm{Li}$ and colleagues ${ }^{3}$ have presented long-term survival ( $>5.5$ years) of a patient with oligometastatic intracranial disease 2 years after initial treatment of an epithelioid mesothelioma. The surgical management included radical pleurectomy and decortication with intraoperative heated chemotherapy (cisplatin, gemcitabine), followed by 4 cycles of adjuvant chemotherapy (cisplatin, pemetrexed). During surveillance, no evidence was found of intrathoracic recurrence; however, neurologic symptoms prompted magnetic resonance imaging of the brain, which identified a $2.4-\mathrm{cm}$ frontal lobe metastasis. The intracranial recurrence was treated with craniotomy and resection, followed by stereotactic radiotherapy to the surgical bed, rendering the patient disease free for an additional 3.5 years. The authors acknowledge that sarcomatoid mesothelioma has been more often associated with intracranial metastasis than epithelioid histologic features. Disappointingly, surveillance strategies for

From the Division of Thoracic Surgery, Massachusetts General Hospital, Boston, Mass.

Disclosures: The author reported no conflicts of interest.

The Journal policy requires editors and reviewers to disclose conflicts of interest and to decline handling or reviewing manuscripts for which they may have a conflict of interest. The editors and reviewers of this article have no conflicts of interest.

Received for publication June 16, 2020; revisions received June 16, 2020; accepted for publication June 17, 2020; available ahead of print June 23, 2020.

Address for reprints: Michael Lanuti, MD, Division of Thoracic Surgery, Massachusetts General Hospital, 55 Fruit St, Founders 7, Boston, MA 02114 (E-mail: mlanuti@mgh.harvard.edu).

JTCVS Techniques 2020;3:363-4

2666-2507

Copyright (C) 2020 The Authors. Published by Elsevier Inc. on behalf of The American Association for Thoracic Surgery. This is an open access article under the CC BY-NCND license (http://creativecommons.org/licenses/by-nc-nd/4.0/).

https://doi.org/10.1016/j.xjtc.2020.06.032

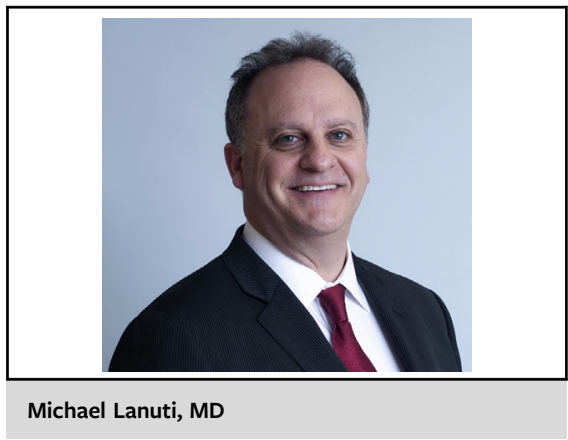

CENTRAL MESSAGE

The evolution of multimodality

improvements in locoregional

treatment of mesothelioma has

invited aggressive therapy op-

tions for oligometastatic disease.

mesothelioma have not been well addressed in National Comprehensive Cancer Network, American Society of Clinical Oncology, ${ }^{4}$ or European Respiratory Society/European Society of Thoracic Society ${ }^{5}$ guidelines, and no recommendations for brain imaging are available.

Locoregional control for pleural mesothelioma has been challenging by virtue of tumor biology and the potential for a large burden of disease. There have been modest improvements in local control, despite modified cytoreductive surgery, which can be primarily attributed to more effective chemotherapy, the addition of bevacizumab for selected patients, and radiation therapy strategies. Combination therapies with checkpoint inhibitors are under investigation in phase I, II, and III clinical trials, with some efficacy. ${ }^{6}$ As local therapy improves, distant metastases could become more prevalent and aggressive local options for oligometastatic disease might be warranted. The authors should be congratulated on their excellent programmatic results and the outcome for this particular patient. Patient selection for multimodality therapy, including appropriate cytoreductive strategies, is paramount and the challenges will be best managed at centers of excellence.

\section{References}

1. Chari A, Kolias AG, Allinson K, Santarius T. Cerebral metastasis of a malignan pleural mesothelioma: a case report and review of the literature. Cureus. 2015;7 e241.

2. El Molla M, Gragnaniello C, Al-Khawaja D, Chiribao-Negri C, Eftekhar B. Cerebral metastasis from malignant pleural mesothelioma. J Surg Case Rep. 2013; 2013:rjt087. 
3. Li SS, Steimer DA, Coy S, Bueno R. Successful treatment of a patient with oligometastatic mesothelioma to the brain. J Thorac Cardiovasc Surg Tech. 2020;3:358-60.

4. Kindler HL, Ismaila N, Armato SG, Bueno R, Hesdorffer M, Jahan T, et al. Treatment of malignant pleural mesothelioma: American Society of Clinical Oncology clinical practice guidelines. J Clin Oncol. 2018:36:1343-73.
5. Scherpereel A, Opitz I, Berghmans T, Psallida I, Glatzer M, Rigau D, et al. ERS/ ESTS/EACTS/ESTRO guidelines for the management of malignant pleural mesothelioma. Eur Respir J. 2020;55:1-24.

6. Gray SG, Mutti L. Immunotherapy for mesothelioma: a critical review of current clinical trials and future perspectives. Transl Lung Cancer Res. 2020;9(suppl 1): S100-9. 